\title{
Effect of Savonius blade height on the performance of a hybrid Darrieus-Savonius wind turbine
}

\author{
Dewi Puspitasari ${ }^{1}$ and Kaprawi Sahim ${ }^{1 *}$ \\ ${ }^{1}$ Mechanical Engineering, Faculty of Engineering, Sriwijaya University, Jl. Raya \\ Palembang-Prabumulih KM. 32 Indralaya 30662, Indonesia. \\ *E-mail: kaprawi@unsri.ac.id
}

\begin{abstract}
A vertical hybrid turbine commonly consists of a Darrieus and Savonius rotor where the Savonius is inside Darrieus turbine. This paper describes the experimental study of hybrid Darrieus-Savonius wind turbines by variation in Savonius blade height. In this case, the effect of the blade height of the Savonius blade was studied experimentally in a subsonic wind tunnel. The effect of the height of a Savonius blade relative to that of Darrieus called blade height ratios $\delta$ was investigated to know the hybrid turbine performance. The performance is represented by power and torque coefficient. The result shows that the hybrid turbine with height ratio greater than unity $\delta=1.4$ gives the highest power $C_{P}=0.20$ and torque coefficient $C_{T}=0.129$. It is investigated that the torque and the power coefficient have a higher value than that of Darrieus turbine, in which the increase in power and torque coefficient are $48 \%$ and $29 \%$, respectively. This hybrid wind turbine with a blade height ratio greater than unity can be considered as an important variable in the wind turbine construction.
\end{abstract}

Keywords: Wind turbine; Darrieus; Savonius; performance; hybrid; blade height ratio.

\section{INTRODUCTION}

The potential for wind energy is abundant [1] and it is natural and can aid in reducing the dependency on the use of fossil fuels. One of the disadvantages of this energy is an intermittent resource, but the availability depends on some conditions like wind velocity, wind speed distribution and fluctuation intensities [2]. Particularly, the turbulent flow of wind speed in urban areas was investigated by Reda et al [3]. in the wind tunnel model. In the exploitation of wind energy, a wind turbine is installed to change it into electrical energy. Two main types of converting machines are horizontal and vertical wind turbine. A wind turbine with a shaft-installed horizontally is called a Horizontal Axis Wind Turbine (HAWT) and the turbine with a shaft-mounted vertically is known as a Vertical Axis Wind Turbine (VAWT). The VAWT is simple since there is no additional apparatus to face the wind velocity, thus reducing tower loads and it has a simpler construction than HAWT. VAWT are grouped into two types: slow running and fast running wind rotors.

The Savonius turbine is basically a drag force driven wind turbines with two semicircular blades, installed to a shaft in the opposite directions. Each blade catches the wind flow and so produces a torque on the shaft so that the rotor rotates. This turbine has lower 
efficiency and lower speed compared to the Darrieus turbine, but it has high torque. Savonius turbine is self-starting type turbines due to high torque at lower speed. The power coefficient of a Savonius wind turbine depends on wind velocity in which it has a maximum performance at wind velocity from 10 to $12 \mathrm{~m} / \mathrm{s}$ and the coefficient of power rises with increasing aspect ratio [4]. Savonius rotor which has two blades has the highest power coefficient compared to that of Savonius with a higher number of blades [5].

The Darrieus rotor is basically a lift force turbine. The rotor comprises two or more airfoils-shaped blades which are fixed to a vertical shaft. The wind strikes the airfoil contours of the blade and creates the lift force which creates a tangential force on the shaft and then the shaft rotates. This kind of turbine is not self-starting type turbines since low torque at low speed, but it has higher efficiency than the Savonius turbine. Darrieus turbine needs external energy to bring the rotor rotates to a minimum speed. The blades of the Darrieus turbine must be in an airfoil shape, in most commonly used likes NACA standard (National Advisory Committee for Aeronautics). The performance of turbines with lower thickness is better than that of the thicker one [6]. This is so because the drag is lower for this type of blade. However, for the reason of structural strength, it is often used a thicker section, in order having the higher lift force. In a certain case, the thin airfoil can be used as a helicopter rotor [7]. Satrio et al. [8] explored the performance of the Darrieus turbine using CFD solver and then compared it to the experimental result.

Hybrid rotors consist of two different rotors installed on the same shaft. Most commonly found that the hybrid systems are in the vertical axis wind turbine. Therefore, Hybrid rotors generally are the turbine with a shaft and two types of blades: Darrieus and Savonius blades. The hybrid wind turbine of Darrieus-Savonius has some benefits over solo Savonius or solo Darrieus rotor, it has a higher efficiency than the Savonius rotor and higher starting torque than the Darrieus rotor. There are three types of configurations of the hybrid Darrieus-Savonius wind turbine: Savonius rotor is inside the Darrieus, Savonius is installed at the top of the Darrieus and Savonius is fixed at the bottom of the Darrieus.

The efficiency of slow running turbines is lower than the fast running turbine. Savonius and Darrieus turbines are often used to generate electricity power with low wind velocity, though they have lower efficiencies than the HAWT. The performance characteristics of VAWT and HAWT is depicted in Figure 1. 


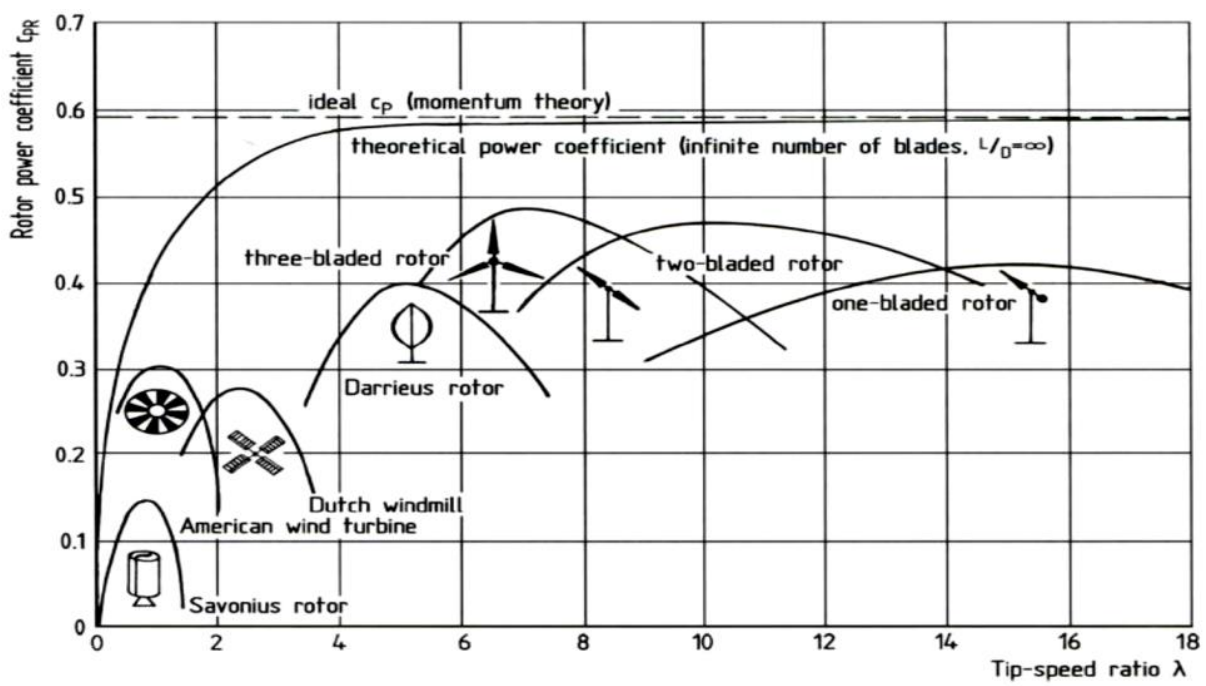

Figure 1. Efficiency of wind power turbines [9].

Theoretical coefficient of power of the horizontal wind turbine called Betz theory, is maximum at $C_{P}=0.593$ and in fact, the actual turbine is always inferior to this value. The power of a wind turbine, $P$, is power coefficient, $C_{P}$ times wind power received by the rotor or written as follows:

$$
P_{T}=C_{P} \frac{1}{2} \rho A V^{3}
$$

where $\rho$ is the density of air, $A$ is the area of the turbine which perpendicular to wind direction and the $V$ is wind speed. The expression of the equation (1) can also be written as:

$$
C_{P}=\frac{P_{T}}{P_{a}}=\frac{T \omega}{1 / 2 \rho A V^{3}}
$$

$P_{\mathrm{a}}$ is wind power, $P_{\mathrm{T}}$ is turbine power $\left(P_{T}=T\right.$. $\omega$ : torque times the angular speed of the turbine).

Torque coefficient is expressed by:

$$
C_{T}=\frac{C_{P}}{\lambda}
$$

$\lambda$ is a ratio between the tangential velocity and air velocity, it is often called Tip Speed Ratio (TSR).

The best performance of the hybrid turbines if the Savonius is inside of the Darrieus turbine [10,11]. A prototype model of the hybrid Darrieus-Savonius wind turbines were developed in a real application for Highway Side by Pandey [12].

The use of unsymmetrical blades of the Darrieus rotor of hybrid Darrieus-Savonius increase the capability of self-starting torque at all azimuthal angles, shown by the value of the good static torque [13]. Gupta et al. [14] studied hybrid Darrieus-Savonius wind turbine with the Savonius was mounted on the upper side of the Darrieus rotor and blade height ratio between Savonius blade and Darrieus blade about 10\%. The combined rotor gave maximum power coefficient 0.51 without overlap of Savonius blade, which is better than the efficiency of the combined Savonius-Darrieus rotor with overlap. In a combined or hybrid DarrieusSavonius turbine, the radius heights of Savonius blade influence the performance 
characteristics of the combined rotor. There is a limit value for the radius ratio so that the combined turbine works optimally $[15,16]$.

Hybrid Darrieus and Savonius water turbine were tested in an irrigation canal to know the effect of the aspect ratio of the Savonius blades which was inside of Darrieus rotor. The significant effects on the performance were observed [17]. Two stages of the Savonius turbine mounted on the top of the Darrieus rotor were tested in water flows. This rotor influences the performance as shown by Kaprawi et al. [18]. The other study of Hybrid Darrieus and Savonius turbine was also studied to know the best orientation of the Savonius rotor inside of the Darrieus rotor [19]. Alam and Iqbal [20] also tested a hybrid DarrieusSavonius rotor in a free flow of water. A hybrid rotor with the Savonius rotor is placed inside in the Darrieus rotor has peak power coefficient of $C_{\mathrm{p}}=0.204$ at TSR $=3.51$ while when as it is placed at outside of the Darrieus rotor, the peak power coefficient is 0.231 at Tip Speed Ratio of 3.76 [21].

From the above literature surveys, it shows that in a hybrid Darrieus-Savonius turbine, the Savonius rotor was installed inside or at the outside of the Darrieus rotor, but we don't find the Savonius rotor installed from the inside until it comes out of Darrieus rotor which may increase the performance. The purpose of the study is to explore the effect of the Savonius blade in a hybrid turbine where the Savonius blades are installed extensively from the inside to the outside of the Darrieus turbine on performance. In this case, the variations of the blade height of the Savonius rotor are studied. The hybrid rotor's performance is then compared to the solo Darrieus turbine. The investigations of the study were experimentally carried out in a subsonic wind tunnel.

\section{EXPERIMENTAL SET-UP AND PROCEDURES}

\section{Torquemeter and Rotor Installation}

A wind tunnel of open type was used in this experimental study. The wind tunnel has $1.2 \mathrm{x}$ $1.2 \mathrm{~m}^{2}$ inlet section including honeycomb flow straightener and the total length $5 \mathrm{~m}$. The flow of wind was produced by a $3 \mathrm{HP}$ electric motor of rotating axial fan which is located at the downstream exit of the flow. The hybrid turbine was installed in the middle of the test section having the area $400 \mathrm{~mm}$ x $400 \mathrm{~mm}$ and length 1,000 $\mathrm{mm}$. The variable speed of the electric motor that drives the fan can make the air velocity variation from 0 to $30 \mathrm{~m} / \mathrm{s}$ in the test area. The velocity of the wind was set at $5 \mathrm{~m} / \mathrm{s}, 7 \mathrm{~m} / \mathrm{s}$ and $10 \mathrm{~m} / \mathrm{s}$ which correspond to Reynolds number $5.66 \times 10^{4}, 7.92 \times 10^{4}$ and $1.13 \times 10^{5}$, respectively. It is noting that the Reynolds numbers were based on the Darrieus rotor diameter. The choice of the above three types of wind velocity was based on the laminar flow in the wind tunnel test section.

Experimental study of the turbine installation is shown in Figure 2 (a), (b) and (c). In measuring the force working on a rotor, the brake type is suitable for a small load, can bring the rotor to rest and the heat energy due friction is used for doing work [22,23]. For that reason, the torque of the turbine was measured with a rope brake dynamometer which consists of one rope wrapped around the pulley which is attached rigidly to the shaft of the turbine. The rope was a nylon string of $0.8 \mathrm{~mm}$ in diameter. One end of the rope tied up to a tubular spring scale while the other end was tied up to the dead load. We used the tubular spring scale in the range of $0-1 \mathrm{~kg}$ accuracy $\pm 1 \%$ since the loads are small. The seals of the 
ball bearing were removed and the balls of the bearing were washed with soapy water to eliminate the grease before installing, so decrease the mechanical friction.

\section{Turbine Parameters}

The aspect ratio is defined as the height of the blade compared to its diameter or

$$
\alpha=\frac{H_{s}}{D_{s}}
$$

where $H_{\mathrm{S}}$ and $D_{\mathrm{S}}$ are the height and diameter of the Savonius rotor respectively. Swept area is given by:

$$
A=H_{D} D_{D}
$$

where $H_{\mathrm{D}}$ and $D_{\mathrm{D}}$ are the height and diameter of Darrieus rotor, respectively.

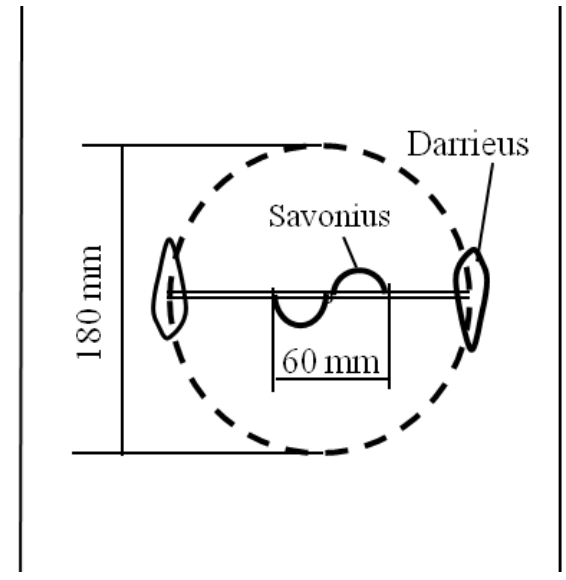

(a)

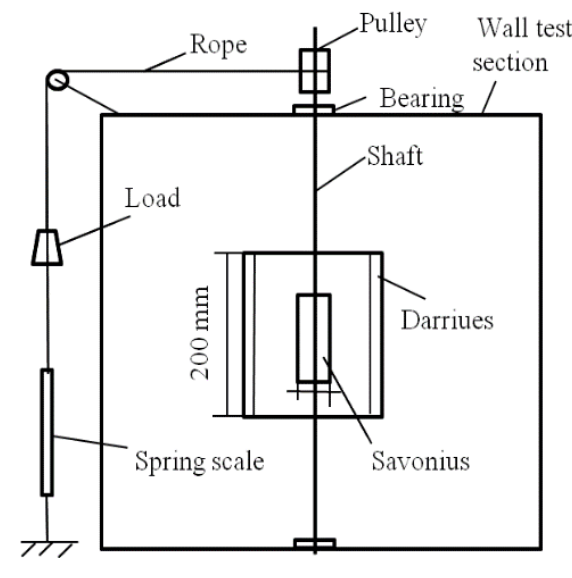

(b)

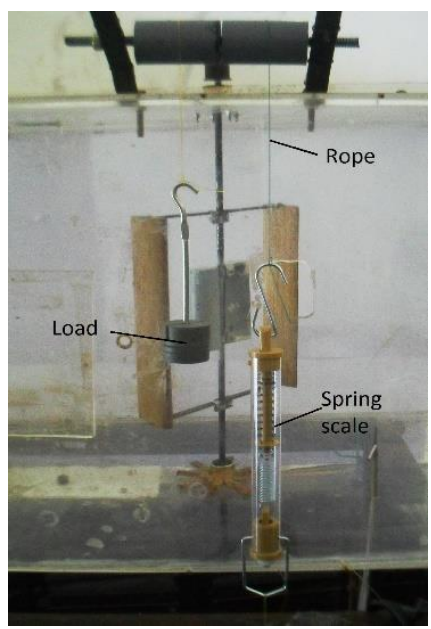

(c)

Figure 2. Components of the hybrid rotor (a) top view, (b) main view and (c) photo of load system. 
The tangential speed of the Darrieus rotor is equal to:

$$
U=\frac{\omega D_{D}}{2}
$$

The dimensionless overlap ratio is represented by:

$$
\beta=\frac{e}{d_{s}}
$$

where $e$ is the overlap and $d_{\mathrm{s}}$ is the diameter of the blade of the Savonius rotor. In a wind tunnel test of wind turbines, the blockage effect which is created by a limited area of wind tunnel test section can lead to distortion of the power performance characteristics of the wind turbine. Therefore, it is necessary to check the wind speed and generated power by blockage ratio.

The Blockage ratio $(B R)$ is given by:

$$
B R=\frac{H_{D} D_{D}}{H_{W} W_{W}}
$$

where $W_{\mathrm{W}}$ is the width and $H_{\mathrm{W}}$ is the height of the wind tunnel test section. Torque coefficient, Power coefficient, and TSR are given, respectively by Bahaj et al. [24] and Jeong et al. [25].

$$
\begin{aligned}
& C_{T}=C_{T T}\left(\frac{V_{T}}{V_{F}}\right)^{3} \\
& C_{P}=C_{P T}\left(\frac{V_{T}}{V_{F}}\right)^{3} \\
& \lambda=\lambda_{T}\left(\frac{V_{T}}{V_{F}}\right)
\end{aligned}
$$

The solidity of Darrieus turbine is given by:

$$
\sigma=\frac{N C}{\pi D_{D}}
$$

Here, $V_{\mathrm{T}}$ is the tunnel wind velocity with the turbine, $V_{\mathrm{F}}$ is the tunnel wind velocity without the turbine. $C_{T}$ is the coefficient of torque in the free stream condition, $C_{P}$ is the coefficient of power in the free stream condition, $C_{P T}$ is the coefficient of power in the wind tunnel condition, $C_{T T}$ is the coefficient of torque in the wind tunnel condition, $\lambda$ is the TSR in the free stream condition and $\lambda_{T}$ is the TSR in the wind tunnel condition. 
Table 1. Geometrical parameters of the rotors.

\begin{tabular}{llcllc}
\hline \multicolumn{2}{c}{ Darrieus rotor } & \multicolumn{4}{c}{ Savonius rotor } \\
\hline Diameter & $D_{\mathrm{D}}, \mathrm{mm}$ & 180 & Diameter & $D_{\mathrm{S}}, \mathrm{mm}$ & 60 \\
Rotor height & $H_{\mathrm{D}}, \mathrm{mm}$ & 200 & Blade diameter & $d_{\mathrm{S}}, \mathrm{mm}$ & 30 \\
Number of blades & $N$ & 2 & Number of blades & $N$ & 2 \\
Chord length & $C, \mathrm{~mm}$ & 50 & Aspect ratio & $\alpha$ & $1.25,3.1,4.5$ \\
& & & Height ratio & $\delta$ & $0.4,1.0,1.4$ \\
Airfoil section & NACA & 0020 & Blade thickness & $t_{\mathrm{s}}, \mathrm{mm}$ & 0.5 \\
Solidity & $\sigma$ & 0.18 & Overlap & $e, \mathrm{~mm}$ & 0 \\
Shaft diameter & $d, \mathrm{~mm}$ & 8 & Shaft diameter & $d, \mathrm{~mm}$ & 8 \\
Airfoil material & & wood & Blade material & & Aluminum \\
\hline
\end{tabular}

\section{Hybrid Rotor}

Hybrid turbine consisted of two wind rotors, Darrieus and Savonius, installed on the same shaft as shown in Figure 3. The Darrieus rotor has two straight blades of a symmetric airfoil section. The choosing of blade chord length must be small enough compared to the test crosssection of the tunnel to avoid the influence of the blockage. The larger the airfoil in comparison to the wind tunnel, the more it will be affected by the blockage.

Savonius rotor consisted of two semi-circular blades which made up of aluminum plate. In this study, the ratio of two rotors radiuses was $R_{S} / R_{D}=0.33$ and it was kept constant for all turbine configurations. Furthermore, the diameter of Savonius rotor $D_{\mathrm{S}}$ was kept constant and height $H_{\mathrm{S}}$ varied, so the aspect ratio became $\alpha=1.25,3.1$ and 4.5 and this aspect ratio correspond to a dimensionless height blade ratio. We introduced this ratio by $\delta=H_{S} / H_{D}$ (Figure 3), so the above aspect ratios correspond to $\delta=0.4,1.0$ and 1.4 respectively. Photograph of the hybrid rotor in the wind tunnel with $\delta=0.4$ and 1.4 is shown in Figure 4 (a) and (b), respectively.

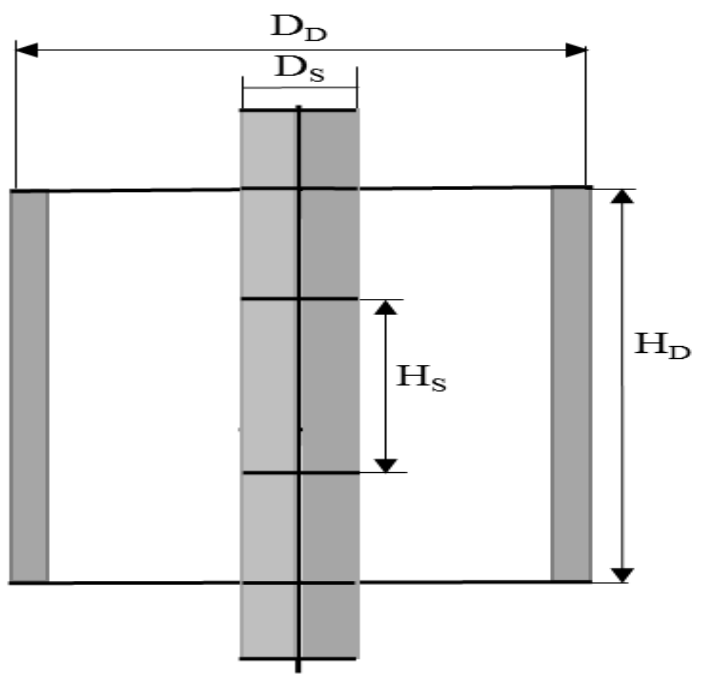

Figure 3. Configuration of blade height ratio, $\delta=H_{\mathrm{S}} / H_{\mathrm{D}}$ 


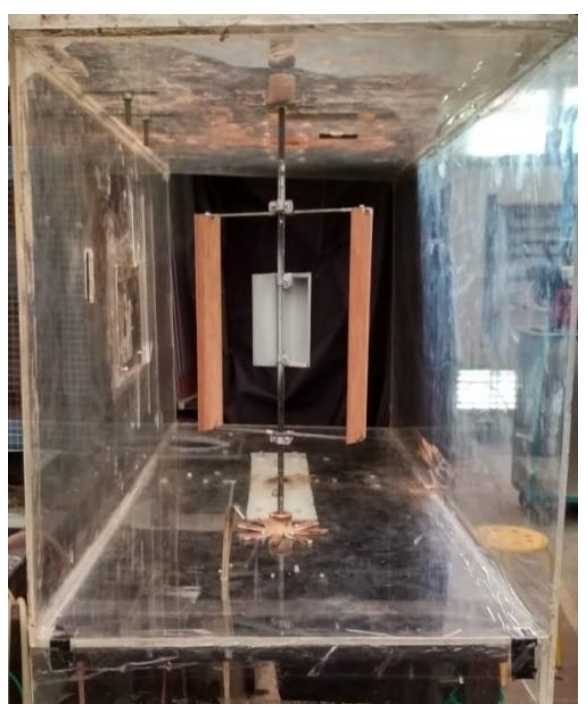

(a). $\delta=0.4$

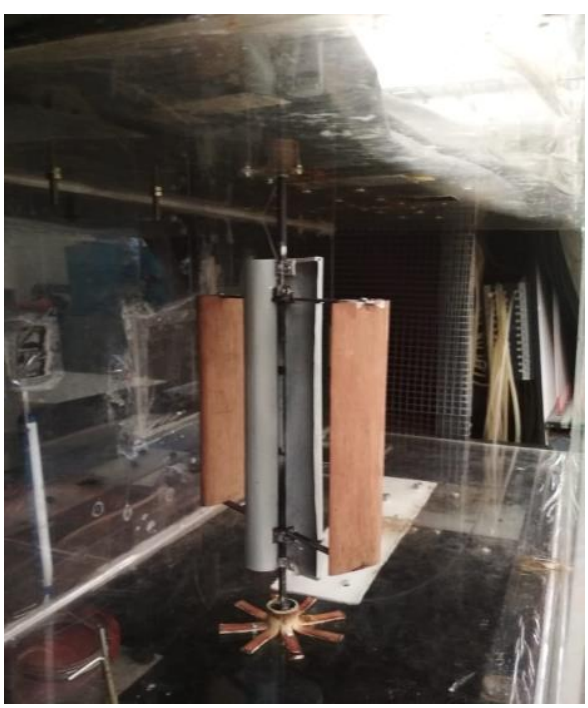

(b). $\delta=1.4$

Figure 4. Photo of hybrid Darrieus-Savonius wind turbine.

\section{Measurement Procedures}

Wind speed was set corresponding to a needed velocity by setting the fan speed and the rotor rotated without load. At no load, the rotational speed achieved maximum value. The number of rotation of the rotor was recorded by a laser tachometer DT2234C with accuracy $\pm 0.05 \%$. Then the rotor was loaded gradually by adding given load on the pan, so the rotation, reduced until it was overloaded and the rotor stopped to rotate. The force balance on the rotor was recorded by a spring scale balance with accuracy $\pm 1 \%$. Wind velocity and air temperature were measured with the help of an anemometer PCE-TA 30 with accuracy $\pm 3 \%$ for velocity and $\pm 1.5^{\circ} \mathrm{C}$ for temperature.

The mean output torque of the hybrid rotor is given by:

$$
T=\left(F_{\mathrm{S}}-F_{\mathrm{m}}\right) \cdot R_{\mathrm{P}}
$$

with $F_{\mathrm{S}}$ is the force reading in spring scale, $F_{\mathrm{m}}$ is the load on the pan and $R_{\mathrm{P}}$ is the pulley diameter. The other parameters are calculated from the Equation. (1) to Equation. (12).

\section{Analysis of the Error}

The error of the experiment is represented by a parameter called uncertainty and calculated from the following equation [26]:

$$
U_{y}=\left[\left(\frac{\partial y}{\partial x_{1}}\right)^{2}\left(U_{x 1}\right)^{2}+\left(\frac{\partial y}{\partial x_{2}}\right)^{2}\left(U_{x 2}\right)^{2}+\ldots+\left(\frac{\partial y}{\partial x_{n}}\right)^{2}\left(U_{x n}\right)^{2}\right]^{1 / 2}
$$

where $y$ is the calculated parameter of the experiments, $U_{y}$ is the uncertainty in the parameter and $U_{x}$ is the uncertainty of each parameter. The parameter $y$ is a given function of the independent variable $x_{1}, x_{2}, \ldots, x_{\mathrm{n}}$. The result of the calculation is given in Table 2 . 
Table 2. The uncertainty of the parameters.

\begin{tabular}{cc}
\hline Parameters & Uncertainty (\%) \\
\hline$C_{P}$ & 5.14 \\
$C_{T}$ & 4.58 \\
\hline
\end{tabular}

\section{RESULTS AND DISCUSSION}

The experiments were carried out for solo Darrieus turbine and for hybrid Darrieus-Savonius turbine with several variations of the blade height ratio. It is noted that for $\delta<1$ the Savonius blade height is lower than that of Darrieus blade height, for $\delta=1$ the Savonius blade height equals to the Darrieus blade and for $\delta>1$ the Savonius blade height equals is greater than that of the Darrieus blade. The performance characteristics are represented in the form of torque and power coefficient versus Tip Speed Ratio $\lambda$. Figure 5 shows the comparative plot of torque coefficient with respect to $\lambda$ at constant wind speed $V=10 \mathrm{~m} / \mathrm{s}$ for all configurations of the rotor. The hybrid Darrieus-Savonius rotor is represented by symbol D-S and D for Darrieus rotor. Furthermore, the torque coefficient of hybrid rotors is then compared to the Darrieus rotor. The torque coefficient is the ratio of torque given by the wind turbine rotor to the available torque in the turbine.

It is seen that for Darrieus turbine, the peak value of the torque coefficient is $C_{T}=0.1$ at tip speed ratio $\lambda=1.2$, then it decreases to zero at $\lambda=2.1$ which is the condition without load. The curves of all turbines rotor have peak values and the curves have steep descending slopes after the peak values are reached. The hybrid turbine rotors have the peak torque coefficient $C_{T}=0.109,0.093$ and 0.129 for height ratio $\delta=0.4,1.0$ and 1.4 respectively. It is clear that a significant value turbine with $\delta=1.4$ which has higher torque than that of Darrieus turbine because the Savonius blade height is $40 \%$ higher the Darrieus blade height. So the cross-section of the blades is at the top and at the bottom of the rotor, thus it seems to be a predominant cross-section since the undisturbed flow strike the blade part located at the top and at the bottom of the rotor. The significant increase in torque coefficient is $29 \%$ compared to the simple Darrieus turbine.

The hybrid rotor with $\delta=0.4$ generates a higher torque coefficient than the Darrieus rotor below $\lambda \leq 1.2$ while for $\lambda>1.2$ the torque coefficient is lower than the Darrieus rotor, so it generates a negative torque. The hybrid rotor with $\delta=1$ produces smaller torque than the Darrieus rotor for $\lambda \leq 1.4$, so it creates the negative torque in beyond this speed, while for higher values of $\lambda$ the rotor has the same torque characteristics. The Savonius rotor is the drag type turbine while the Darrieus is lifted type turbine and by combining both turbines, each turbine works according to their own characteristics. The forces differences between the advancing and returning blade of the Savonius turbine due to the different drag coefficient create a torque on the rotor which makes the turbine rotates. A large value of $\delta$ represents a large aspect ratio $\alpha$ of the Savonius rotor. Savonius turbines with high aspect ratio produces low loss due to the influence of the tips of the blades thus increases the turbine performance [27]. The blades of the Darrieus rotor produce the lift forces due to the presence of the angle of attack. Each position of the blades rotates one rotation $0-360^{\circ}$ produce the different lift force or net lift force and this force difference produce torque. The net lift is large enough 
which make peripheral velocity of the rotor is greater than the wind velocity or TSR greater than unity and then the momentum was delivered from the turbine to the wind flow, reducing the moment of the turbine.

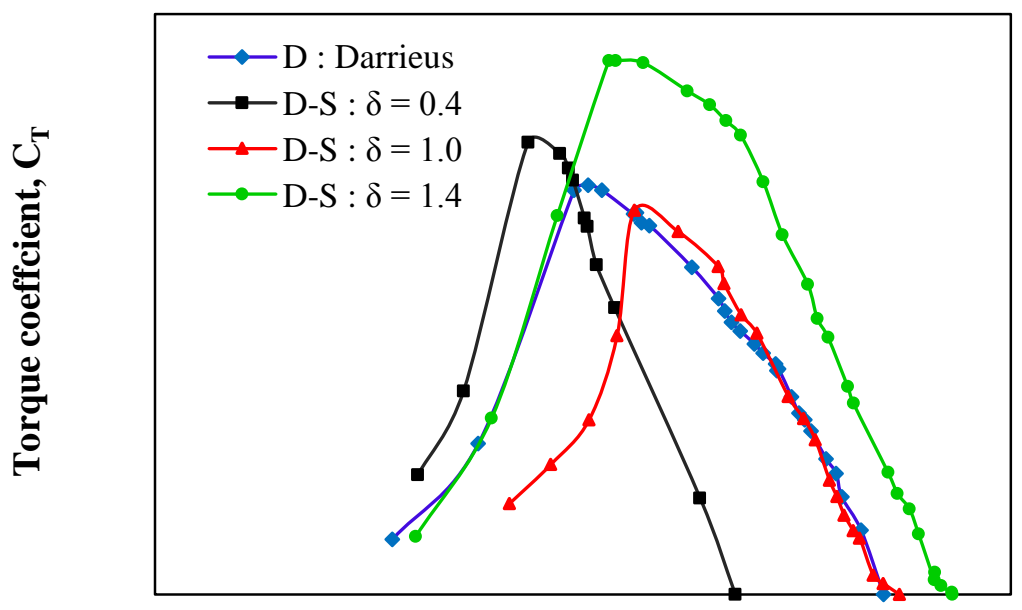

Tip Speed Ratio

Figure 5. Torque coefficient for $V=10 \mathrm{~m} / \mathrm{s}$.

The hybrid turbine comprising rotors are interacting with each other. By combining the Savonius rotor into the Darrieus rotor, the maximum torque coefficient may increase or decreases which depend on the blade height ratio and the same thing with the operation speed. When the hybrid rotor runs at a lower speed than the Darrieus turbine, so the Savonius acts as an aerodynamic brake at the rotor. It seems that it occurs when blade height ratio less than or equal to unity. The speed and the torque can increase higher than that of the conventional Darrieus turbine for the blade height ratio greater than unity. For $\delta>1$ there are the areas of Savonius blade that are exposing to the free stream. These areas increase the pressure on the blade and hence the torque of the rotor. The net torque on Savonius blades is due to the difference of the drag force between the advancing blade (i.e concave side) and the returning blade (i.e convex side). It is generally noted from the literature that by combining the Savonius rotor into the Darrieus, so it may increase self-starting torque of the Darrieus turbine at low speed. In this hybrid rotor with all blade height configurations, we can't observe the performance at low speed since the Darrieus-Savonius turbine is too small in dimension and the torque meter is not sensitive to very low loads. It is the reason that there is no data on the left part in Figure 5.

The power coefficient of the rotor for the wind speed of $V=10 \mathrm{~m} / \mathrm{s}$ is plotted in Figure 6. The characteristic curves for all the investigated hybrid turbine have similar shapes. It is observed that the Darrieus rotor, Hybrid rotor with $\delta=0.4$ and $\delta=1$ have practically the same peak values of power coefficient, while the operation speed ranges are different. The lowest operation speed range is observed in the hybrid rotor with $\delta=0.4$ since the curve shifts to the lower $\lambda$. Similarly, for the hybrid turbine with $\delta=1.0$, the speed range is lower than the Darrieus turbine, but it's higher than that of the turbine with $\delta=0.4$. So it seems that the larger the blade height the higher the drag force of the Savonius blade which makes higher 
speed. However, the Darrieus turbine shows still better speed range than both hybrid rotors. The inclusion of the Savonius rotor with $\delta=0.4$ and 1 into the Darrieus rotor have a small effect on the power coefficient and speed limit.

The significant effect is shown on the hybrid turbine with Savonius blade height higher than the blade height of a Darrieus turbine or rotor with $\delta=1.4$ since the curve profile is higher than that of Darrieus turbine. Thus the power coefficient and the speed range are higher than the Darrieus rotor. The peak value of $C_{P}=0.20$ is observed, which is higher than the power coefficient of the Darrieus rotor which has a maximum power coefficient $C_{P}=$ 0.135 . So the increase is about $48 \%$. Besides that, this hybrid rotor has a wider operating speed limit. In this case, there is $40 \%$ of Savonius blade area exposed to the free stream flow which acts as a drag type principle and this area can extract a lot of kinetic energy. The operating range of the hybrid rotor exceeds the operating of the Darrieus rotor which means that the rotor has good aerodynamic behavior. The hybrid rotor with $\delta \leq 1$ is a bad condition for creating energy since its power coefficients are not better than the Darrieus rotor. The increase of blade height ratio from $\delta=0.4$ to 1 means the increase of the area of the blades of Savonius rotor so that more power is absorbed by the turbine and it increases the tangential speed of the hybrid rotor. The values of the power coefficient seem to be similar since the increase in blade area is proportional to the increase in absorbed power thus the power coefficient curves are slightly different in values as it can be shown by the Eqn (2). The case of $\delta=1.4$, it seems the increase of the power is more dominant than the increase of the blade area.

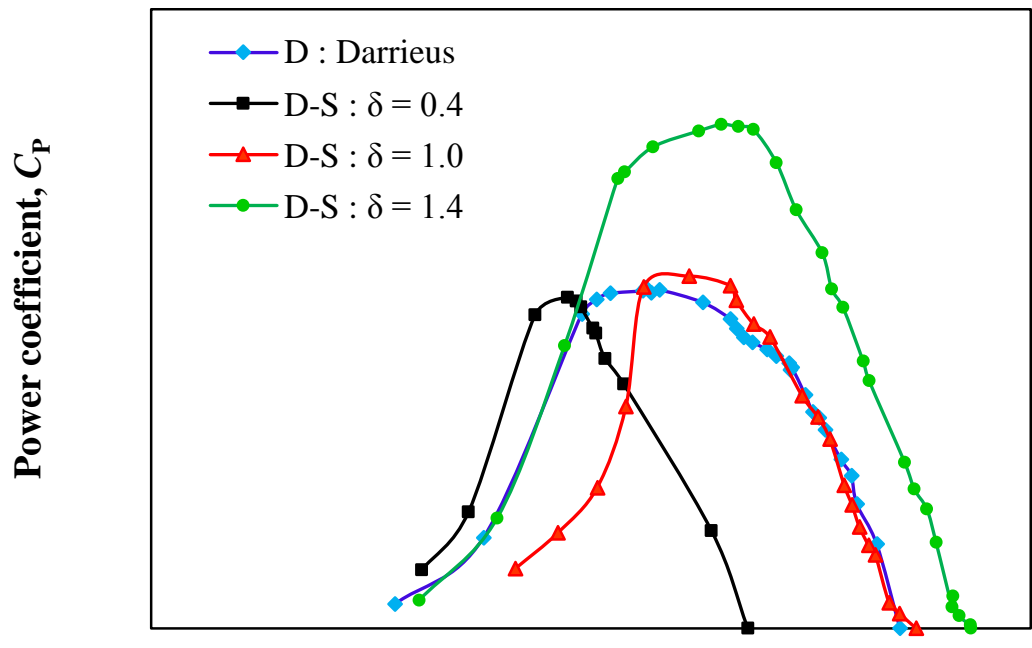

Tip Speed Ratio

Figure 6. Power coefficient for $V=10 \mathrm{~m} / \mathrm{s}$.

As it is explained in the above that the better performance of the hybrid turbine with $\delta=1.4$ in terms of torque and power coefficient is observed, then it is necessary to explore the influence of wind speed variation on the performance of the turbine. That is why Figure 6 is presented to explore the influence of the wind speed to the torque coefficient. Three wind speed of $V=5 \mathrm{~m} / \mathrm{s}, 7 \mathrm{~m} / \mathrm{s}$ and $10 \mathrm{~m} / \mathrm{s}$ were used to test the hybrid rotor. The curves show that lower wind speed $V=5 \mathrm{~m} / \mathrm{s}$, the rotor has a peak torque coefficient $C_{T}=0.075$ at $\lambda=0.7$ 
while for $V=7 \mathrm{~m} / \mathrm{s}$ the peak value $C_{T}=0.08$. So it seems that the lower the wind speed the lower also the torque coefficient and the operation speed tends to decrease since the curve shift to the left part. However, at low wind speed, the rotor still can run to generate considerable torque and a wide range of speed can also be achieved. The effect of the Darrieus rotor in hybrid rotors is still predominant since the rotor can operate in $\lambda>1$. Comparing the results to the result of the rotor with wind speed $10 \mathrm{~m} / \mathrm{s}$, higher wind speed gives a higher torque coefficient.

The higher the wind speed, the higher the kinetic energy of the wind and the more turbine torque produced. The force generated by high wind speed produces a high lift force in the Darrieus turbine and produces a high drag force on the Savonius turbine, which forces high torque and high spin on the turbine. Conversely, at low wind speed $\mathrm{V}=5 \mathrm{~m} / \mathrm{s}$ it produces a low tangential force on the turbine rotor so that the torque and rotation are also low compared to high wind speed. At low-speed $\lambda<1$, the rotor can still operate and the torque is quite high since the Savonius blade part located in the Darrieus rotor receives the undisturbed flow of wind. In this condition, the Savonius blades play an important role in creating high torque at low rotor's speed. A solo Savonius is always run at low-speed $\lambda<1$ since the rotor is drag force type turbine, in which the rotor speed never exceeds the wind speed. At wind speed $\mathrm{V}=7$ and $10 \mathrm{~m} / \mathrm{s}$, the rotor operates at high-speed $\lambda>1$ which show that the lift forces play an important role Darrieus rotor. The rotor acts as a solid rotor and no undisturbed wind flow give forces to the Savonius blade located in the middle of the Darrieus rotor.

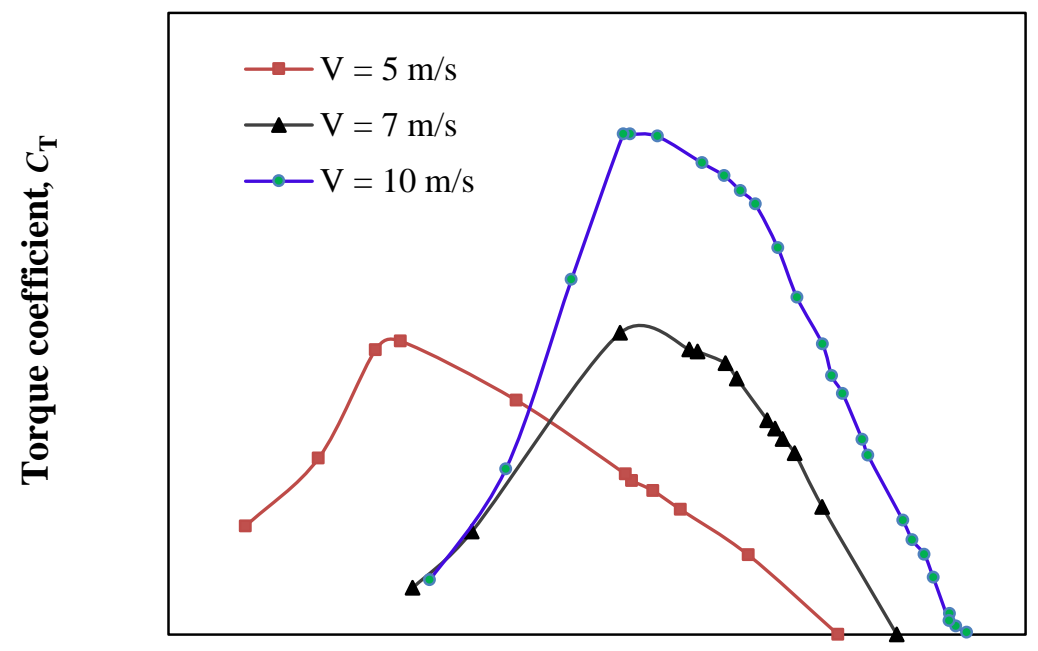

Tip Speed Ratio

Figure 6. Torque coefficient for $\delta=1.4$.

The power coefficient of the hybrid rotor with $\delta=1.4$ and for different wind speed is plotted in Figure 7. In comparing the hybrid rotor performance for two wind speeds, the significant difference of peak value in power coefficient is observed in which $C_{P}=0.07$ for $V=5 \mathrm{~m} / \mathrm{s}$ and $C_{P}=0.12$ for $V=7 \mathrm{~m} / \mathrm{s}$. Comparing these power coefficients with the power coefficient for the rotor of $V=10 \mathrm{~m} / \mathrm{s}$ (Figure 5), these hybrid turbines have lower peak value. Starting from the idle condition of the turbine, where $C_{P}=0$, the power coefficient increase with the decrease of $\lambda$ and then reach a peak value, after that it decreases to an overload 
condition at low speed. The higher the speed of the wind the higher speed of the rotor and the higher the power coefficient, but the higher the wind speed the dropping rapidly speed of turbines.

It is known that the power coefficient is the ratio of measured turbine power by available wind power. A significant increase in the power coefficient is caused by the more dominant of two variables force on the turbine blade and the rotor rotation compared to the wind speed variable. In this condition, the energy loses of mechanical due to friction and hydraulic loses types are small compared to the energy gained by forces working on the blades. For the wind speed $V=7$ and $10 \mathrm{~m} / \mathrm{s}$, the turbine speeds are greater than unity which show that the Darrieus rotor is more dominant than the Savonius since the lift type turbine speed is greater than wind velocity. If $V=5 \mathrm{~m} / \mathrm{s}$, it seems that the Savonius rotor in the hybrid system is more dominant since the speed $\lambda<1$ where the drag force type turbine slower than the wind speed. However, for all height ratios, the Darrieus is still predominant in its operations since the Tip Speed Ratio $\lambda>1$.

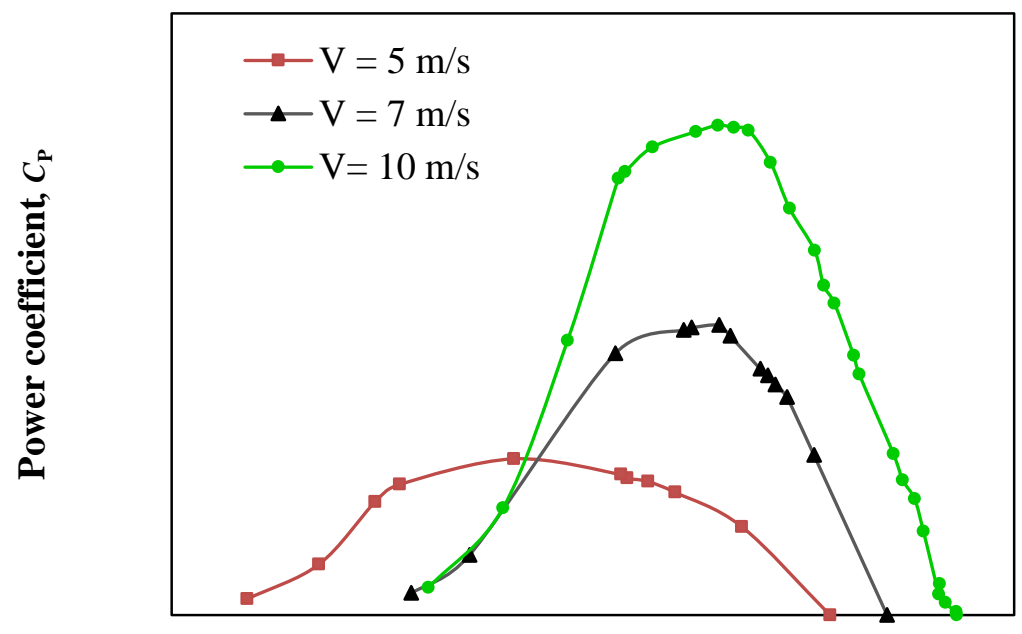

Tip Speed Ratio

Figure 7. Power coefficient for $\delta=1.4$.

It is noting that the turbine power varies with the cube of the wind speed. If the rotor of the wind turbine turns too slow, most of the wind will past undisturbed through the gap between the turbine blades. Therefore, a wind turbine must operate at optimum Tip Speed Ratios (TSR) to extract as much power out of the wind as possible. Thus maximum power coefficients occur at optimum TSR. So from the power coefficient curves show that the optimum TSR depends on the wind speed since maximum power coefficients occur at different TSR for different wind speed. 


\section{CONCLUSIONS}

From the above discussions, it is concluded as follows:

1. The Hybrid Darrieus-Savonius wind turbine with $\delta=1.4$ has the highest performance in comparison with the conventional Darrieus turbine and the hybrid turbine with the blade height ratio is lower or equal to unity.

2. The blade height ratio influences the hybrid Darrieus-Savonius wind turbine performance characteristics. This study indicates that the hybrid Darrieus-Savonius wind turbine which combines lift-force type and drag-force type blades can attain a higher torque and power coefficient than that of a conventional Darrieus turbine. The hybrid turbine with the blade height ratio $\delta=1.4$ have good performance characteristics and the rotor can generate a higher speed than the Darrieus turbine. The power and the torque coefficient increase by $29 \%$ and $48 \%$ respectively.

3. The hybrid turbine with $\delta=1.4$ is more suitable for low wind speeds because it has wide operating speed. However, for all height ratios, Darieus is still predominant in its operations since the Tip Speed Ratio $\lambda>1$.

4. The hybrid Darrieus-Savonius wind turbine with the Savonius mounted from inside extends to the outside of the Darrieus rotor may increase the performance and this hybrid rotor needs further investigations especially in low speeds.

\section{ACKNOWLEDGEMENTS}

Thanks to Sriwijaya University that supported the research through Riset Unggulan Profesi with grant number : 0109.

\section{REFERENCES}

[1] Kamil K. Wind energy: Progress and potential. Energy Sources. 2004;26:95-105.

[2] Joselin Herberta GM, Iniyanb S, Sreevalsanc E, Rajapandiand S. A review of wind energy technologies. Renewable and Sustainable Energy Reviews. 2007;11:11171145.

[3] Reda E, Rozli Z, Harun Z. Large eddy simulation of wind flow through an urban environment in its full-scale wind tunnel models. Journal of Mechanical Engineering and Sciences. 2017;11(2):2665-2678.

[4] Mahmoud NH, El-Haroun AA, Wahba E, Nasef MH. An experimental study on improvement of Savonius rotor performance. Alexandria Engineering Journal. 2012;51(1):19-25.

[5] Sheldahl RE, Feltz LV, Blackwell BF. Wind tunnel performance data for two- and three-bucket Savonius rotors. Sandia Laboratories, USA 1978; Sand 76-0131 Under Act AT/29-11: 789.

[6] Migliore PG, Fritschen JR. Darrieus wind turbine airfoil configurations. Solar Energy Research Institute, USA. 1982.

[7] Yaakub MF, Wahab AA, Abdullah A, Nik Mod NAR, Shamsuddin SS. Aerodynamic 
prediction of helicopter rotor in forward flight using blade element theory. Journal of Mechanical Engineering and Sciences. 2017;11(2):2711-2722.

[8] Satrio D, Ketut Aria Pria Utama I, Mukhtasor. The influence of time step setting on the CFD simulation result of vertical axis tidal current turbine. Journal of Mechanical Engineering and Sciences. 2018;12(1):3399-3409.

[9] Wilson RE, Lissaman PBS. Applied aerodynamics of wind machines 1974.

[10] Siddiqui A, Hameed A, Mian SN, Khatoon R. Experimental Investigations of hybrid vertical axis wind turbine. In $4^{\text {th }}$ International Conference on Energy, Environment and Sustainable Development (EEDS2016), 2016.

[11] Rassoulinejad-Mousavi SM, Jamil M, Layeghi M. Experimental study of a combined three bucket H-rotor with savonius wind turbine. World Applied Sciences Journal. 2013;28(2):205-211.

[12] Pandey A, Devi R. Study and development of hybrid wind turbine for highway side application. International Journal of Advanced Research in Electrical, Electronics and Instrumentation Engineering. 2017;6(9):6763-6767.

[13] Bhuyan S, Biswas A. Investigations on self-starting and performance characteristics of simple $\mathrm{H}$ and hybrid $\mathrm{H}-$ Savonius vertical axis wind rotors. Energy Conversion and Management. 2014;87(87):859-867.

[14] Gupta R, Biswas A, Sharma K. Comparative study of a three-bucket Savonius rotor with a combined three-bucket Savonius-three-bladed Darrieus rotor. Renewable Energy. 2008; 33(9): 1974-1981.

[15] Xiaoting L, Sauchung F, Baoxing O, Chili W, Christopher YC, Kaihong P. A computational study of the effects of the radius ratio and attachment angle on the performance of a Darrieus-Savonius combined wind turbine. Renewable Energy. 2017; 113: 329-334.

[16] Sahim K, Santoso D, Puspitasari D. Investigations on the effect of radius rotor in combined Darrieus-Savonius wind turbine. International Journal of Rotating Machinery. 2018.

[17] Sahim K, Ihtisan K, Santoso D, Sipahutar R. Experimental study of darrieus-savonius water turbine with deflector: Effect of deflector on the performance. International Journal of Rotating Machinery. 2014.

[18] Kaprawi S, Santoso D, Sipahutar R. Performance of combined water turbine Darrieus-Savonius with two stage Savonius Buckets and single deflector. International Journal of Renewable Energy Researh. 2015;5(1):1-5.

[19] Kyozuka Y. An Experimental Study on the Darrieus-Savonius Turbine for the tidal current power generation. Journal of Fluid Science and Technology. 2008; 3(3): 439449.

[20] Alam MJ, Iqbal MT. A low cut-in speed marine current turbine. Journal of Ocean Technology. 2010;5(4):49-62.

[21] Kumar A, Nikhade A. Hybrid kinetic turbine rotors: A review. International Journal of Engineering Sciences and Advanced Technology. 2014;4(6):453-463.

[22] Gopinath R. Design of a rope brake dynamometer. Middle-East Journal of Scientific Research. 2014; 20(5):650-655.

[23] Gibson G, Liht F. Brakes and Dynamometers 19.1. in Retrieved from http://theeye.eu/public/WorldTracker.org/Physics/Theory of Machine: 732-773.

[24] Bahaj AS, Molland AF, Chaplin JR, Batten WJM. Power and thrust measurements of 
marine current turbines under various hydrodynamic flow conditions in a cavitation tunnel and a towing tank. Renewable Energy. 2007; 32(3): 407-426.

[25] Jeong H, Lee S, Kwon SD. Blockage corrections for wind tunnel tests conducted on a Darrieus wind turbine. Journal of Wind Engineering and Industrial Aerodynamics. 2018;179; 229-239.

[26] Nakra BC, Chaudry KK. Instrumentation measurement and analysis. $3^{\text {rd }}$ ed. New Delhi: McGraw Hill; 2009.

[27] Vicente J, Antonio H, Prisco A. A review on the performance of Savonius wind turbines. Renewable and Sustainable Energy Reviews. 2012; 16(5), 3054-3064. 